\title{
On Some Necessary Conditions of Learning
}

\author{
Ference Marton \\ Department of Education \\ Göteborg University, Sweden \\ Ming Fai Pang \\ Faculty of Education \\ The University of Hong Kong
}

\begin{abstract}
The purpose of this article is to identify some necessary conditions of learning. To learn something, the learner must discern what is to be learned (the object of learning). Discerning the object of learning amounts to discerning its critical aspects. To discern an aspect, the learner must experience potential alternatives, that is, variation in a dimension corresponding to that aspect, against the background of invariance in other aspects of the same object of learning. (One could not discern the color of things, for instance, if there was only one color.) The study results illustrate that what students learn in a sequence of lessons is indeed a function of the pattern of variation and invariance constituted in that sequence. All teachers make use of variation and invariance in their teaching, but this study shows that teachers informed by a systematic framework do it more systematically, with striking effects on their students' learning.
\end{abstract}

In recent discussions of design experiments, ${ }^{1}$ theoretical weakness has been highlighted as a major problem, especially by diSessa and Cobb (2004) who pointed out the importance of being able to distinguish between what is necessary and what is contingent. Much of the criticism of design experiments in Dede's (2004) discussion can be read as a way of making explicit some of the consequences of the failure to make this distinction. Kelly (2004), the other discussant in the same paper symposium, phrased the problem very clearly:

Correspondence and requests for reprints should be sent to Ference Marton, Department of Education, Göteborg University, Box 300, SE 40530 Göteborg, Sweden. E-mail: ference.marton@ ped.gu.se

\footnotetext{
${ }^{1}$ We do not make any distinction between design experiments, design-based research, or design studies.
} 
Until we can begin to discover and model the necessary components of learning ... design study output is prone to be dismissed as mere "narrative" ... [and] the data are merely "anecdotal." Our descriptions cannot, over the long haul, remain at the level of contingency. When we move toward identifying what is necessary in the situation, then the methodology becomes more mature, scientifically. It is in the connection of the contingent to the necessary where the real work of theory-building occurs. (p. 125).

However, the failure to distinguish between what is necessary and what is contingent in design experiments or in educational research in general is not only a problem for research and the researcher. Above all, it is a problem for teachers in their everyday work. It is not possible to act professionally without being able to distinguish between what must be done and what might be done to achieve one's professional aims and carry out one's professional duty.

Hence, there is confluence between the interests of the researcher and those of the teacher in being able to distinguish between what is necessary and what is contingent. In this article, we present a framework that claims to do exactly that. We illustrate how this framework can be used to make sense of the relation between what is happening in different classrooms and what the students gain from participating in the classroom events.

We illustrate the question of the necessary and the contingent mainly by showing that students learn to the extent that necessary conditions are met, to the extent that learning is made possible. As the study has certain important commonalities with and certain important differences from design experiments, as characterized in recent discussions (see, e.g., Barab \& Squire, 2004; Cobb, Confrey, diSessa, Lehrer, \& Schauble, 2003; Collins, Joseph, \& Bielaczyc, 2004; Kelly, 2003; Shavelson, Phillips, Towne, \& Feuer, 2003), we situate our reporting in the context of those discussions.

\section{LEARNING STUDY}

The study that we report in this article is a hybrid between a design experiment as characterized by Brown (1992) and Collins (1992) on one hand and a Japanese lesson study as characterized by Yoshida (1999) and Stigler and Hiebert (1999) on the other. We call our particular arrangement a "learning study," which can be characterized as follows. A group of between two and six teachers comes together to find a way of making it possible for students to appropriate a specific object of learning. An object of learning is a specific insight, skill, or capability that the students are expected to develop during a lesson or during a limited sequence of lessons. There are two aspects of the object of learning: the direct and the indirect objects of learning. The former is defined in terms of content, such as demand and supply, language tones, irony, and so forth, and the latter refers to the kind of capability that the students are supposed to develop such as being able to define, being able to give 
examples, or being able to discern the critical aspects of novel situations (see Marton \& Tsui, 2004, p. 4).

The teachers who work together with a researcher or on their own choose a particular object of learning that is central to the curriculum that they all teach and that is known to cause difficulties for the students. Once the object of learning is chosen, the group starts to plan the lesson(s) with a special focus on making it possible for the students to appropriate the object of learning. The main resources in the search for an answer are the teachers' own experiences in dealing with this particular object of learning, previous research, the particular framework that they use to identify the necessary conditions for their specific learning target, and-above all — the exploration of the prior understanding of their students or the exploration of the extent to which the object of learning and/or its prerequisites have been appropriated by the students before teaching starts. The students' initial mastery of the object of learning is called the lived object of learning (1). The focus of the teachers is on the way in which the specific object of learning will be handled in terms of the aspects of the direct object of learning that will vary and those that will remain invariant during the sequence of events in the lesson(s). The focus on what varies and what is invariant derives from the specific framework the teachers are making use of; and the choice of other factors, such as whole-class teaching, group work, and form of representation, and the use of textual or electronic resources is subordinate to the teachers' design of the pattern of variation and invariance. The finalized design is the intended object of learning (Marton \& Tsui, 2004, p. 22).

The intended object of learning does not effect the learning of the students in itself, but the way in which it is realized does. One of the teachers is chosen by the group to carry out the lesson while the other members of the group observe. Usually, the lesson is video recorded, and what the students have learned is probed by written questions and interviews. The lesson is analyzed in terms of whether it was possible to appropriate the object of learning through the pattern of variation and invariance that was constituted by the teacher and the students jointly. This is the basic idea of the framework (which is sometimes called "the variation framework") that underlies this study, as we elaborate later. What varies and what is invariant both constrains learning and makes it possible. This is the enacted object of learning that is described through the necessary conditions for the appropriation of the object of learning. From the answers of the students to the written and oral questions given after the lesson, we can characterize the lived object of learning (2). ${ }^{2}$ The group of teachers then compares the outcome with the prelesson results: That is, they compare the lived object of learning at the two points in time. The

\footnotetext{
${ }^{2}$ It should be obvious from this presentation that the main difference between our concept of the object of learning and the far more common concept of the learning objective is that whereas the latter refers to the goal, target, or aim of learning, the former also refers to the conditions and outcome of learning. The idea is to describe the goal, conditions, and results in commensurable terms.
} 
gains and the absence of gains can then be related to what has happened in the classroom, especially as the enacted and the lived objects of learning are described in commensurable terms: that is, in terms of variation and invariance.

The group may then come up with some suggestions about what can be improved in the lesson(s) and methods for the implementation of improvements. Another teacher is nominated and carries through the new version of the lesson according to the same procedure.

The cycle is repeated up to four times, and the study is always concluded by documentation. Delayed achievement tests and interviews are quite common. This model has been used in many classes in Hong Kong and Sweden during the last 4 years (see, e.g., Lo, Marton, Pang, \& Pong, 2004).

An alternative way of finding out how different ways of handling the object of learning affect the students' learning is that members of the group of teachers teach on the grounds of the same lesson plan: That is, they deploy the same intended object of learning in parallel. Variation in the enacted object of learning, in how different teachers realize the same lesson plan, can then be related to differences between classes in the outcome-the lived object of learning (2). To increase the variation in the enacted object of learning, other teachers who are teaching the same object of learning but not using the same lesson plan are invited to form a comparison group. It is this design alternative that we used in the study we report here.

\section{Two Distinguishing Features of the Learning Study}

As mentioned previously, a learning study is a hybrid form of the Japanese lesson study and a design experiment. We point to two characteristic features of the learning study that it shares more with lesson studies than with design experiments.

1. Learning studies are limited to one lesson or a few lessons and aim to find a powerful way to teach a particular object of learning. Compared with the view of Collins et al. (2004) that an important goal in a design experiment is to cover as many variables as possible, the learning study (like the lesson study) has a much narrower focus and addresses only the question of how the specific object of learning can be taught in a powerful way.

2. In a design experiment, the theory or framework is initially in the hands of the researchers themselves, as is the design. In a learning study, teachers are expected to use the framework as a tool and a resource and to set up the design themselves. They are also expected to use the framework in the implementation of the design and in their interaction with the students to help them make sense and use of what the students say and then to choose how to respond. Hence, as with a lesson study, the teachers are the designers. The researcher's role is merely to assist the teachers in the appropriation of the framework to be used. 


\section{Object of Learning}

As mentioned previously, the object of learning has two aspects: the direct and the indirect objects of learning. These two aspects are analytically separated, although neither can exist without the other. The content (the direct object) can never be the aim or the outcome of learning in itself. It is the capability of using that content (the indirect object) that is the target or result. When we use the term object of learning, both of these aspects are included.

Direct object of learning. The direct object of learning that we chose in the learning study we report here was "the effect of a simultaneous change in demand and supply on price." The teachers selected this topic for the following two reasons. First, it includes some of the most difficult concepts for school children at this level. It has been reported that many candidates in public examinations are unable to discern that both the supply of and the demand for a commodity are affected in a given question that requires the comparison of the magnitude of changes in both demand and supply (Hong Kong Examinations Authority, 1992, 1995). Second, it is one of the most fundamental concepts in economics and is vital for students to develop an understanding of the economic aspects of the world around them.

Market prices change due to supply changes, demand changes, or both. Based on commonsense understanding, quite a number of people see a change in the market price of a commodity as an effect of a change either in demand or supply, but few people take into account that price changes may be caused by a simultaneous change in both demand and supply.

In economics, when both supply and demand change in the same direction simultaneously, whether the price goes up or down depends on the relative magnitude of the change in demand and supply. In general, there are three possible effects of a simultaneous change in demand and supply on price. First, when the increase (decrease) in demand is greater than the increase (decrease) in supply, then the price of the commodity will go up (down); second, when the increase (decrease) in demand is smaller than the increase (decrease) in supply, then the price of the commodity will go down (up); and finally, when the magnitude of change (increase/decrease) of demand and supply is the same, then the price will remain unchanged.

To recapitulate, to develop a powerful understanding of how the price of a commodity will change as a result of a simultaneous change in demand and supply, the relative magnitude of the changes in demand and supply must be taken into consideration.

Indirect object of learning. The indirect object of learning is the capability that we expect the students to develop. The direct object of learning as, for instance, "the effect of a simultaneous change in demand and supply on price,"- that is, the content as such—does not reveal what the students should be capable to 
achieve after the lesson(s). We must decide whether we expect them, for instance, to be able to remember the definition or determine the new equilibrium price by using a graph representation when the numerical value of the changes in demand and supply are given or whether they should be able to make sense of novel situations when the market price changes in terms of the relative magnitude of changes in demand and supply. For the following reasons, we settle for the second alternative.

One of the main functions of schooling today is to enable students to handle novel situations in powerful ways. Different people may perceive the same situation in different ways, and the same situation may have a different meaning for each person. Furthermore, people do not act in relation to a situation as such but in relation to the situation as they perceive it. Marton and Booth (1997) referred to many studies that have demonstrated that powerful ways of handling situations are to a great extent a function of powerful ways of perceiving those situations. Bransford, Brown, and Cocking (2000) summarized a considerable body of research that has shown that the most important difference between experts and novices has to do with the way in which they see novel situations in their field of expertise. Bransford and Schwartz (1999) referred to Broudy's (1977) notion of "knowing with" as a particular form of knowledge in addition to "knowing that" (replicative knowledge) and "knowing how" (applicative knowledge). Knowing with is the knowledge that is used to make sense of, see, and interpret the world. Our previous experiences (including concepts, principles, and theories learned in school) can be considered as tools for the perception of novel situations (see also Broudy, 1988). So whereas the economic phenomenon (the effect of a simultaneous change in supply and demand on price) embedded in various situations is the direct object of learning in this study, a certain way of seeing the economic phenomenon in those situations is the indirect object of learning.

What, then, is "a way of seeing something," and how can we characterize the differences between different ways of seeing the same thing? According to the conceptual framework that underlies this study and as presented in an embryonic form by Marton and Booth (1997) and in a more developed version by Marton and Tsui (2004), differences in the perception of the same situation originate from the fact that different people may notice, pay attention to, or focus on different features of the same situation. A way of seeing a situation, or a particular meaning of a situation, is thus defined in terms of the features that are noticed and focused on simultaneously.

\section{Learning to See in a Certain Way as a Function of Experienced Variation and Invariance}

What does it take to notice or focus on a particular feature? Half a century ago, Gibson and Gibson (1955) contrasted two classes of theories of perceptual learning. One of the classes they called "enrichment theories." According to such theories, memory images and inferences are constantly being added to initially meager 
sensations. From this theoretical viewpoint, perceptual learning is a constructive process. The other class is that of differentiation theories. According to differentiation theories, initially vague percepts become more and more differentiated through perceptual learning: That is, more and more differences are discerned in what is perceived. Those differences lie both within what is perceived and between what is perceived and what has been perceived earlier. From this theoretical standpoint, perceptual learning is a process of discrimination and discernment.

The framework that we adopted in this study resembles this second class of theories. Noticing and giving attention to a feature of a situation amounts to the discernment of that feature, and the discernment of a feature amounts to experiencing a difference between two things or between two parts of the same thing. This is because we cannot discern quality $X$ without simultaneously experiencing a mutually exclusive quality $\sim X$. Take "sight" as an example. A child's sight might be normal or excellent, or they might be shortsighted. A shortsighted child cannot, however, separate their shortsightedness, or simply their sight, from the world that they see. The two are inseparable until the day the child receives their first pair of glasses. When this happens, the child separates sight and the world because one of the two (the world) remains invariant, whereas the other (sight) changes from "sight without glasses" to "sight with glasses." All of a sudden, the child can discern the latter, which is an entirely novel experience. Moreover, the child can potentially discern sight as a dimension of variation within which two different values have been discerned. By wearing the glasses in different places at different times, the child can conclude that glasses mean a general improvement in sight across different conditions. When the child occasionally takes the glasses off, they experience the simultaneity in variation between wearing glasses on one hand and being able to see well or not being able to see well on the other. We can now specify four necessary conditions for perceptual learning. (For a more elaborate discussion of these principles, see Marton \& Tsui, 2004, pp. 16-17.)

1. Contrast: A quality $X$ cannot be discerned without the simultaneous experience of a mutually exclusive quality $\sim X$. (When this condition is met, the child can discern both sight without glasses and sight with glasses.)

2. Separation: A dimension of variation, which can take on different values, cannot be discerned without other dimensions of variation being invariant or varying at a different rate (whereas sight changes, the world remains the same).

3. Generalization: A certain value, $X_{i}$ in one of the dimensions of variation $X$ cannot be discerned from other values in other dimensions of the variation unless $X_{i}$ remains invariant while the other dimensions vary. (The child's sight with glasses is invariantly better when the child looks at different, or varying, things).

4. Fusion: The simultaneity of two dimensions of variation cannot be experienced without experiencing the two dimensions varying simultaneously. (As the 
taking off and putting on of the glasses varies simultaneously with sight, so the simultaneity of the two states can be discerned.)

We have now described what is required for the learner to discern dimensions of variation, the values in those dimensions, the generality of those values, and the simultaneity of the dimensions of variation for the first time. Yet how can that which is learned be used in novel situations? The idea is that once one has discerned those different things, one would be likely to be able to discern them in novel situations in the future. To discern something for the first time requires the experience of a specific pattern of variation, and so does discerning them again and again. If a person's sight were to dramatically worsen, then he or she could only discern it by remembering what his or her sight was like earlier, or the person must experience the two states simultaneously. New values in the dimensions of variation can be discerned only through the simultaneous experience of variation. The same is true of the discernment of previously determined dimensions of variation in novel situations.

Affordances for learning. In the previous section, we have specified some necessary conditions for learning by which is meant learning in the sense of becoming able to discern and distinguish certain qualities, dimensions of variation in which qualities vary, and relations between dimensions of variation. The necessary conditions are necessary in the sense that a learner must experience a certain pattern of variation and invariance to be able to discern a quality, a dimension of variation, or a relation. A teacher can create the pattern of variation and invariance that the student must experience to learn (in the sense of becoming able to discern), but just because the pattern is there to be experienced does not necessarily imply that it is experienced by the learner. In the words of Gibson (1986), it is an affordance. Thus, the presence of a pattern of variation and invariance, as seen by the teacher or the researcher, is not a sufficient condition of learning in the previously mentioned sense. However, one must ask oneself whether this presence is a necessary condition. For some learners, it may not be. There is always the possibility that, taking our example of the shortsighted child, the child's previous experiences (for instance, of seeing better) together with their present experience (of not seeing very well) may allow them to experience the necessary variation, even if this variation is not present in the situation as seen by the teacher or the researcher. However, we can argue that the presence of a particular pattern of variation and invariance in a certain situation is a necessary condition of learning to discern a particular aspect of a particular object of learning as a function of the experience of that situation.

In other words, even though the experience of a certain pattern of variation and invariance is necessary for a given instance of learning, and even though the presence of that pattern of variation and invariance is necessary for some students to have that experience, other students can draw on experiences before that situation, and hence, for them, the presence of the pattern of variation and invariance are nei- 
ther a necessary nor a sufficient condition of learning. For this reason, on the group level, the presence/absence of a necessary condition of learning is not reflected in terms of the presence/absence of learning but in terms of variation in the likelihood of learning.

\section{Aim of the Study}

If we bring the direct and indirect objects of learning together, then we can formulate the object of learning in this specific case: being able to see changes in price in terms of simultaneous changes in demand and supply.

The aim of this study was to explore the relation between the extent to which students appropriate this object of learning on one hand and the pattern of variation and invariance inherent in the sequence of lessons during which this is expected to happen on the other hand.

\section{METHOD}

We investigated the preceding question by means of learning study, a hybrid of design experiments and the Japanese lesson study model. We enhanced the likelihood of the presence of the necessary pattern of variation and invariance by partly choosing teachers whose attention had previously been called to the importance of critical variation and invariance in the way the object of learning is constituted through their previous work in classroom with the framework we describe in this article. These teachers formed the "target group." There were also teachers who had not come across the explicit idea of the relation between the students' learning and the pattern of variation and invariance in teaching. These teachers formed the "comparison group." We compared student learning and pattern of variation and invariance both between and within these two groups to illuminate the relation between the two (student learning and the pattern of variation and invariance). This means that although we (the researchers) introduced independent variation in conditions, we did not explore the relation between this introduced variation and the learning outcomes. Instead, we explored the relation between variation in what is actually happening in different classrooms and learning outcomes. This means that the conditions are not defined in advance but found out by studying what actually happens.

\section{Participants}

Five teachers and five classes participated in the study. All of the teachers had at least 5 years experience of teaching economics at the secondary level. Their age varied from 29 to 33 years. Two were women and three were men. Two of the teachers had earlier worked with the framework briefly outlined previously. They 
formed what we call the target group. The three other teachers had not previously come across this framework, and they formed the comparison group.

When the study was carried out, there was a streaming system in effect in the Hong Kong schooling system, with schools being divided into three bands. To make the results as comparable as possible, all of the classes were drawn from Band 1, which is supposed to embrace the most academically able students. There were 123 boys and 46 girls participating in the study.

\section{Conduct of the Study}

Each group of teachers developed a lesson plan comprising three lessons. It took two sessions and 5 hours to produce these plans. The lesson plans defined the intended object of learning and implied what the students would be able to learn from the lesson(s) if the teacher followed the plan. The teachers brought the direct and indirect objects of learning together when they formulated the intended object of learning. They expressed what they were trying to achieve in terms of the conditions that they considered to be necessary to achieve it.

The intended object of learning cannot be derived from the direct object of learning and the general nature of the indirect object of learning. Had we obtained it in this way, we would have arrived at the same intended object of learning regardless of whether the students were at primary, secondary, or tertiary level. Thus, we had to take the level of previous understanding of the object of learning into consideration. The most straightforward way of doing this was to explore the extent to which the students had mastered the object of learning before the actual study. Of course, if the object of learning was completely new and could not even have built on something that they had learned earlier, then this could not have been done. However, in our study, this was not the case - the Grade 10 students in the five different classes that participated in the study had studied economics before and had covered some fundamental concepts in demand and supply such as the fact that market price is determined by the interaction between market demand and supply.

\section{Data Collection}

All of the students were given two written questions and $30 \mathrm{~min}$ in which to answer them before the teachers started to work on planning the lessons. The questions were framed in such a way that to answer them required the discernment of demand, supply, change in demand and supply, the magnitude of change in demand and supply, and changes in the relative magnitudes. The students were asked to answer the questions again after the sequence of lessons to ascertain how (if at all) their understanding of the (direct) object of learning had changed.

\section{Question 1}

Some years ago, original video compact discs (VCDs) were rather expen- 
sive, and many people turned to buying pirated VCDs. There were many shops that sold pirated VCDs. Over the past few years, the Customs and Excise Department of the Hong Kong government has put much effort into stopping the illegal trade in pirated VCDs, and we can now find fewer shops that sell pirated VCDs. However, it is interesting to note that the price of pirated VCDs has not increased but has remained more or less the same as it was in the past. Why? Can you explain this?

Question 2

In 1997, a new bird flu virus H5N1 was found in humans in Hong Kong. A total of 18 cases were reported and 6 people died. To stop the spread of the bird flu, the government immediately killed about 1.2 million chickens in the territory. However, it was surprising to find that after this move, the price of live chickens in the market did not increase but instead fell. Why? Please explain.

All of the lessons were videotaped and subsequently transcribed verbatim.

\section{Analysis of Data}

The tests. We analyzed the students' answers phenomenographically. We put all of the answers together in a "pool of meaning," and differentiation was made between qualitatively different explanations in terms of the aspects of the scenario that were discerned and focused on simultaneously. We captured the variation between the different forms of explanation by means of the set of categories A to E. (For a more detailed account of this method, see Marton \& Booth, 1997, chap. 5).

We also applied the framework that the teachers used in the target group to the description of the differences in the students' answers. This means that we characterized differences in the lived object of learning in terms of what critical aspects (e.g., demand, supply, relative magnitude) the students had discerned and focused on: that is, experienced variation in.

The lessons. Again, we analyzed the way in which the object of learning was dealt with in the different classes in terms of the framework that the teachers used in the target group. In this way, we characterized the enacted object of learning in terms of variation and invariance in critical aspects. Hence, we described the enacted and the lived objects of learning in commensurable terms.

\section{RESULTS}

\section{Lived Object of Learning (1)}

When exploring the understanding of changes in price as a function of simultaneous changes in demand and supply before the teaching sequence, five qualita- 
tively different ways of making sense of the direct object of learning were found. The five categories that were formulated for capturing the variation in answers applied to both questions asked.

Change in price as a function of

A. The attributes of the good (e.g., changes in the quality of the pirated VCDs, market mechanisms, demand, supply not discerned).

B. Changes in demand (e.g., changes in how many people wanted to buy the pirated VCDs, supply not discerned).

C. Changes in supply (e.g., changes in the number of pirated VCDs available, demand not discerned).

D. Changes in demand and supply (e.g., changes in the number of pirated VCDs available and the number of people wanting to buy them, magnitude not discerned).

E. The relative magnitude of the changes in supply and demand (e.g., whether there was a greater increase in the number of pirated VCDs available or the number of people who wanted to buy them).

In other words, the categories differed in the aspects of the scenario that were discerned and focused on simultaneously. To discern a particular aspect implies an experience of variation in that particular respect. A change in demand, for instance, is experienced in contrast to the alternative option of no change. The relative magnitude of change, such as "changing more than ...," is experienced in contrast with other options such as "changing less than. ..." Although the learner experiences variation in the discerned aspects, other aspects are invariant in the sense that they are taken for granted (see Table 1).

We considered answers that fell into the last category to be model answers. Here is an example.

Some years ago, many people were buying pirated VCDs because original VCDs were expensive. However, during the past few years, the Hong Kong

TABLE 1

Patterns of Experienced Variation and Invariance That Correspond to Different Ways of Explaining Change in Price

\begin{tabular}{lccccc}
\hline Category & Qualities of Goods & Supply & Demand & Relative Magnitude of Change & Price \\
\hline A & V & I & I & I & V \\
B & I & I & V & I & V \\
C & I & V & I & I & V \\
D & I & V & V & I & V \\
E & I & V & V & V \\
\hline
\end{tabular}

Note. $\quad \mathrm{V}=$ variation; $\mathrm{I}=$ invariance. 
Customs and Excise has tried to stop the illegal trade in pirated VCDs, and there are now fewer shops that sell pirated VCDs. Therefore, we can see that the supply of pirated VCDs decreased. However, people's willingness to buy pirated VCDs also decreased because they were afraid of being arrested. It was true that there was still the willingness to buy pirated VCDs, but it was decreasing. We thus see the demand also decreased. In this case, we have to look at how much the demand and supply decreased. The level of decrease of the demand and supply were almost the same, and therefore the price did not change much. (Class 2, Student 15)

We can see that change in demand, change in supply, and the relative magnitude of the two were discerned. The student who wrote this answer must-according to the framework-have experienced simultaneous variation in the relevant aspects.

The frequency distribution between the two groups can be seen in Table 2. As we are interested in the conceptions that the students were able to express, if a student expressed different conceptions in relation to the two questions, then the "highest" conception was counted.

We can see that all of the students considered market mechanisms, although about half of them identified demand only, or changes in demand only, as the explanation for the problems rather than change in supply, which is very much in line with earlier studies. Only one student discerned the relative magnitude of the changes in demand and supply. Judging from these results, the discernment of relative magnitude was a new capability for practically all of the students in the two groups.

\section{Intended Object of Learning—Lesson Plan}

In the following, we compare the lesson plans developed by the two groups of teachers. Both groups made use of variation and invariance, as do all teachers. However, the two teachers in the target group made use of their knowledge of the

TABLE 2

Distribution of Conceptions for the Written Task-Pretest

\begin{tabular}{lcrrrr}
\hline & \multicolumn{2}{c}{ Target Group $^{a}$} & & \multicolumn{2}{c}{ Comparison Group $^{b}$} \\
\cline { 2 - 3 } \cline { 5 - 6 } Conception & Occurrence & $\%$ & & Occurrence & $\%$ \\
\hline A & 0 & 0.0 & & 0 & 0.0 \\
B & 30 & 39.0 & & 45 & 2.9 \\
C & 1 & 1.3 & & 2 & 47.8 \\
D & 46 & 59.7 & & 44 & 1.0 \\
E & 0 & 0.0 & & 1 & \\
\hline
\end{tabular}

Note. $\quad \chi^{2}(3, N=169)=3.071, p=.381$ (i.e., $\left.p>.05\right)$.

${ }^{\mathrm{a}} n=77 .{ }^{\mathrm{b}} n=92$. 
systematic variation framework and let only those aspects vary at the same time to which they want to draw the students' attention while keeping other aspects invariant. They also made sure that all the relevant aspects were focused on by varying them one at a time and brought them together subsequently.

The teachers in the comparison group, who were ignorant of the variation framework, did similar things but not consciously and systematically as the teachers in the target group. The lesson plan produced by the three teachers in the comparison group did not ensure that the necessary conditions for attending the relevant aspects of the phenomenon and bringing them together were present in the lessons.

Intended object of learning in the target group. The teachers wanted to establish a context for learning, hoping to bring to the students an experience of an abstract economic concept in a meaningful way. To do so, they planned to present students with the case study of the face mask market when severe acute respiratory syndrome hit Hong Kong to exemplify how a simultaneous change in demand and supply would affect the price of a commodity in a context of which the students had direct experience. Having one case study across different lessons was thought to afford a better focus on how the interaction between a change in demand and supply affects price change rather than a focus on the product itself.

In the first part of the lesson, the teacher would try to separate the change in demand from the change in supply. To put it in another way, the supply would be kept unchanged or invariant, and only the demand would be changed. By referring to the various scenarios as portrayed by the relevant news clippings, the demand for face masks would first increase moderately, then further increase greatly, and finally decrease. After that, the teacher would introduce a similar treatment on supply while keeping demand invariant, with the selection of those news clippings related to a change in the supply of face masks only. The supply would first increase to a small extent, then increase greatly, and eventually decrease. By introducing variation in the absolute magnitude of change in demand or in supply, the teacher could help students discern this dimension and how it would affect the price of a good.

With a view to achieving what the teachers had originally discussed, the difficulty that students had in conceptualizing the idea of the relative magnitude of change in demand and supply, the teachers would then introduce simultaneous variation in the magnitude of increase in both demand and supply by inviting students to explore the three possible alternative results with the aid of three different diagrams. To help students to conceptualize the notion of relative change in magnitude in a more effective manner, the teacher would further put the three possible cases into a combined diagram and demonstrate the dynamic changes in the relative magnitude of change in demand and supply. Changes in price can be seen as a function of changes in the relative magnitude of changes in supply and demand as shown by the continuous movement of the supply curve while keeping the magnitude of change in demand constant. 
In addition to the case when both demand and supply increase, the teacher would provide students with the reverse case (when both demand and supply decrease). Furthermore, the teacher would introduce the cases when demand and supply change in opposite directions (when demand increases and supply decreases or when demand decreases and supply increases) in which there would be a definite answer for the price change without the need to consider the critical aspect of the relative magnitude of change in demand and supply (as the changes of the two curves would affect the price in the same direction). This would serve as a good contrast to the previous cases in which both demand and supply changed in the same direction, which would direct students' focal awareness toward the importance of the critical aspect of relative magnitude of change in demand and supply when determining the price change. The teacher would conclude by restating the key points of the lessons and drawing students attention to the object of learning.

According to the variation framework, to discern a dimension of variation, the learner must experience variation in that dimension, and applied to this particular case, the students must experience variation in the relative magnitude. Given that the teachers followed the plan, it should have been possible for the students to discern the relative magnitude of the changes in supply and demand. Thus, the target group chose to separate change in demand, the magnitude of change in demand, change in supply, and the magnitude of change in supply and then fuse the magnitude of change in supply and in demand into one dimension of variation that corresponded to the relative magnitude of the change in demand and supply.

The intended object of learning in the comparison group. The lessons would begin with a revision exercise that aims at helping the students develop a basic understanding that some events would affect consumers (demand), whereas some would affect producers (supply). Similar to the target group, in the lessons, the teacher would then try to separate the change in demand from the change in supply by keeping the supply invariant while changing the demand. However, instead of using the same good throughout the lesson, the teacher would make use of the slimming service for the case of increase in demand and the bus service to contextualize the case of decrease in demand.

Subsequently, the teacher would vary the supply while keeping demand invariant with the use of the example of the slimming service. However, unlike the lesson plan of the target group, the supply would change in one direction only: That is, only the case of increase in supply would be introduced. After that, the teachers would continue to use the example of the slimming service to introduce simultaneous variation in the magnitude of increase in both demand and supply. Students would be invited to explore the three possible cases with the aid of three different diagrams. It would then be followed by the introduction of a simultaneous variation in the magnitude of decrease in both demand and supply with the use of the example of the bus service. By doing so, the teacher would draw students' attention to and help them discern the crit- 
ical aspect of the object of learning: that is, the relative magnitude of change in demand and supply. The students would be invited to present their answers, and the teacher would then draw a conclusion for the lessons.

Similarities between the intended objects of learning in the two groups. The intended objects of learning - as defined by the lesson plans-were not very different in the two groups. Both planned the separation of the change in the demand side, the separation of the change in the supply side, and the fusion of the relative magnitude of change in demand and supply. How is it then possible that the intention of the learning study group to follow the variation theory did not make any obvious difference? The fact is that all teachers make intuitive use of variation in their teaching. Actually, there can be no teaching without variation, and the differences in the efficiency of teachers can be characterized in terms of the efficiency of the patterns of variation and invariance that they adopt in their teaching (Marton \& Morris, 2002; Marton \& Tsui, 2004). What variation theory offers, therefore, is simply a more coherent, explicit, and systematic framework for making use of variation and invariance

\section{Differences between the intended objects of learning in the two} groups. The differences between the two lesson plans may not have been striking, but when seen from the point of view of variation framework, it was decisive.

1. Different goods are used as examples between the cases of increment and decrement in the comparison group. The target group kept the same good (face masks) invariant in all cases. However, the comparison group used one good, the slimming service, for the case of increase in demand and supply, while using another good, the bus service, to contextualize the case of decrease in demand and supply. This means that increment and decrement cannot be separated from the goods, and the two are not brought together.

2. Cases with different directions of change in supply and in demand are missing in the comparison group. The target group included different directions of change in supply and in demand. However, the comparison group considered the case in which the demand and supply simultaneously changed in the same direction only but did not examine the case in which demand and supply simultaneously changed in opposite directions, that is, when demand decreases and supply increases and when demand increases and supply decreases. This means that the simultaneous variation in change in demand and supply is curtailed as far as direction is concerned.

3. There is no variation introduced in the absolute magnitude of change in demand or in supply in the comparison group. The target group introduced different absolute magnitude of change when showing the increase and decrease in demand or supply. In contrast, the comparison group did not do so. This means that no vari- 
ation was constituted in this dimension, and thus, the absolute magnitude of change in demand or in supply could not be discerned.

4. The variation in the relative magnitude of change is illustrated by using three different diagrams in the comparison group, whereas the teachers in the target group, in addition to the different diagrams, also planned to represent the dynamic changes in the relative magnitude of change in demand and supply with the use of a combined diagram.

According to the variation framework, if the intended object of learning is implemented in the classes of the target group, then the students will have a greater opportunity to appropriate the capability of discerning the effect of a simultaneous change in demand and supply on price. If the intended object of learning is implemented in the comparison group, then the students will be less able to develop the capability of discerning the effect of a simultaneous change in demand and supply on price. I now show whether these predictions came true.

\section{Lived Object of Learning (2)}

Based on the intended object of learning, comparing the target and the comparison group, we predicted that in the target group, it would be possible for more students to develop an understanding of the effect of a simultaneous change of demand and supply on price than in the comparison group. This was because of the four major differences in the two designs, as we highlighted earlier. One can see from Table 3 that the results give strong support for our expectation: The difference between the target group and the comparison group in outcome, that is, in the lived object of learning (2), was highly significant, $\chi^{2}(3, N=169)=64.197, p<.001$. As far as the target group was concerned, we did not predict that all the students would master the task, merely that it would be possible for them to do so. Most of the students did master the task, which was consistent with the prediction. As far as the comparison

TABLE 3

Distribution of Conceptions in the Written Task in the Posttest

\begin{tabular}{lccccr}
\hline & \multicolumn{2}{c}{ Target Group $^{a}$} & & \multicolumn{2}{c}{ Comparison Group $^{b}$} \\
\cline { 2 - 3 } Conception & Occurrence & $\%$ & & Occurrence & $\%$ \\
\hline A & 0 & 0.0 & & 0 & 0.0 \\
B & 2 & 2.6 & & 13 & 14.1 \\
C & 0 & 0.0 & & 1 & 56.5 \\
D & 6 & 7.8 & & 52 & 28.3 \\
E & 69 & 89.6 & & 26 & \\
\hline
\end{tabular}

Note. $\chi^{2}(3, N=169)=64.197, p<.001$.

${ }^{a} \mathrm{n}=77 .{ }^{b} \mathrm{n}=92$. 
group was concerned, we declared that it would be less possible for the students in this group to master the task. Some students did manage to master the task, but many did not. There are three potential explanations for why students under this condition developed an understanding that was strictly not possible from the experience that the lesson plan projected. First, some students may have mastered the task before the lesson (which was indeed the case in some instances); second, some students may have had previous experiences that, together with the experiences that they encountered during the lessons, were sufficient to help them to master the task; and third, the lesson may have developed in ways that differed from the lesson plan, that is, from the intended object of learning.

Thus, to make sense of the differences in outcome, of the differences in the lived object of learning, the intended object of learning is not sufficient. We must examine the enacted object of learning. We look at the target group first (see Table 4).

\section{Lived and Enacted Objects of Learning in the Target Group}

It appears that Class 2 performed better than Class 1 despite the two teachers having jointly developed the lesson plan. We thus need to compare the intended and the enacted objects of learning within each case and between the two cases.

Class 1. Teacher 1 in Class 1 followed the lesson plan faithfully and carried out every major step. The only observed discrepancy between the enacted and intended objects of learning was that when he introduced the variation in the absolute magnitude of change in supply, in addition to the face mask example stated in the lesson plan, he used the additional example of a vegetable to illustrate how a decrease in its supply after a typhoon would cause a rise in the price, as he realized that some of the students might not have grasped the relation between a change in supply and its effects on price.

TABLE 4

Intragroup Comparison Between Classes in the Target Group:

Posttest-the Lived Object of Learning (2)

\begin{tabular}{lrrrrr}
\hline & \multicolumn{2}{c}{ Class 1 } & & \multicolumn{2}{c}{ Class 2 } \\
\cline { 2 - 3 } \cline { 5 - 6 } Conception & No. & $\%$ & & No. & $\%$ \\
\hline $\mathrm{A}$ & $0 / 38$ & 0.0 & $0 / 39$ & 0.0 \\
$\mathrm{~B}$ & $2 / 38$ & 5.3 & & $0 / 39$ & 0.0 \\
$\mathrm{C}$ & $0 / 38$ & 0.0 & & $0 / 39$ & 0.0 \\
$\mathrm{D}$ & $5 / 38$ & 13.2 & & $1 / 39$ & 2.6 \\
$\mathrm{E}$ & $31 / 38$ & 81.6 & $38 / 39$ & 97.4 \\
\hline
\end{tabular}


The pattern of variation and invariance inherent in the enacted object of learning is summarized in Table 5. We now look at the other teacher under the same experimental conditions.

Class 2. Teacher 2 observed Teacher 1's lesson, and there was a discussion afterward that resulted in some changes in the intended and enacted objects of learning. The two lessons could be seen as two cycles within the learning study. Nevertheless, the lesson conducted by Teacher 2 was very close to that conducted by Teacher 1, which had followed the lesson plan closely. There were only two major differences in the enacted object of learning between the two teachers.

First, Teacher 2 kept the context of the study invariant by using the same goods (face masks) throughout the lessons without adding any other examples to exemplify the concepts, whereas Teacher 1 had used the extra example of the vegetable to show how a decrease in supply would raise the price of a commodity.

The most important difference observed, however, was how the dynamic changes in the relative change of magnitude in demand and supply were represented. After observing Teacher 1's lesson, Teacher 2 decided to devise a computer program to demonstrate the dynamic changes in the relative magnitude of change

TABLE 5

Patterns of Variation and Invariance (Temporal Sequence) Inherent in the Lessons in Classes 1 and 2

\begin{tabular}{|c|c|c|c|c|c|c|}
\hline Supply & $\begin{array}{c}\text { Change in } \\
\text { Magnitude } \\
\text { (Supply) }\end{array}$ & Demand & $\begin{array}{l}\text { Change in } \\
\text { Magnitude } \\
\text { (Demand) }\end{array}$ & Goods & $\begin{array}{c}\text { Change in } \\
\text { Magnitude } \\
\text { (Relative) }\end{array}$ & Price \\
\hline \multicolumn{7}{|l|}{ Class 1} \\
\hline \multirow[t]{2}{*}{ I } & & V & & A & & V \\
\hline & I & & V & A & & V \\
\hline \multirow[t]{2}{*}{ V } & & I & & A & & $\mathrm{V}$ \\
\hline & V & & I & A & & $\mathrm{V}$ \\
\hline \multirow[t]{2}{*}{ V } & & I & & $A \& B$ & & V \\
\hline & V & & V & A & $\mathrm{V}^{\mathrm{a}, \mathrm{b}}$ & $\mathrm{V}$ \\
\hline \multicolumn{7}{|l|}{ Class 2} \\
\hline \multirow[t]{2}{*}{ I } & & V & & A & & V \\
\hline & I & & V & A & $\mathrm{V}^{\mathrm{c}}$ & V \\
\hline \multirow[t]{2}{*}{$\mathrm{V}$} & & I & & A & & V \\
\hline & V & & I & A & $\mathrm{V}^{\mathrm{c}}$ & V \\
\hline \multirow[t]{2}{*}{$\mathrm{V}$} & & V & & A & & V \\
\hline & V & & V & $\mathrm{A}$ & $\mathrm{V}^{\mathrm{c}, \mathrm{d}}$ & V \\
\hline
\end{tabular}

Note. $\mathrm{V}=$ variation; $\mathrm{I}=$ invariance.

allustrated by three separate diagrams and one common diagram. ${ }^{b}$ Including all four combinations of increasing versus decreasing supply and demand. 'Diagrams implemented with information technology as dynamic representations. ${ }^{\mathrm{d}}$ Including all four combinations of increasing versus decreasing supply and demand. 
in demand and supply. Instead of using the blackboard, the teacher used information technology in such a way that the simultaneous movements of the two curves were exhibited in a dynamic manner to show the relation between the relative magnitude of change in demand and supply and price changes (see Figure 1). The change in price was demonstrated to be dependent on changes in the relative magnitude of changes in supply and demand, as was shown by the continuous movements of the supply and demands curves from left to right (or the other way around). This enabled the students to experience the simultaneous variation in both aspects more readily and directly.

The pattern of variation and invariance that was inherent in the enacted object of learning is very similar to the pattern that was observed in the previous case (see Table 5).

\section{Comparing the Two Classes in the Target Group}

Even though the two series of lessons appeared to be similar in terms of our restricted framework, they obviously differed in many aspects. Table 5 points to only two differences. Of these two differences, one is more easily linked to the students' experience of variation, namely, the difference in how the relative magnitude of changes in demand and supply was represented. In Class 1, changes in the positions of the lines were shown by showing two lines in different positions in the same diagram that yielded different equilibrium prices (see Figure 2), whereas with the computer-implemented version, there were simply two lines that kept

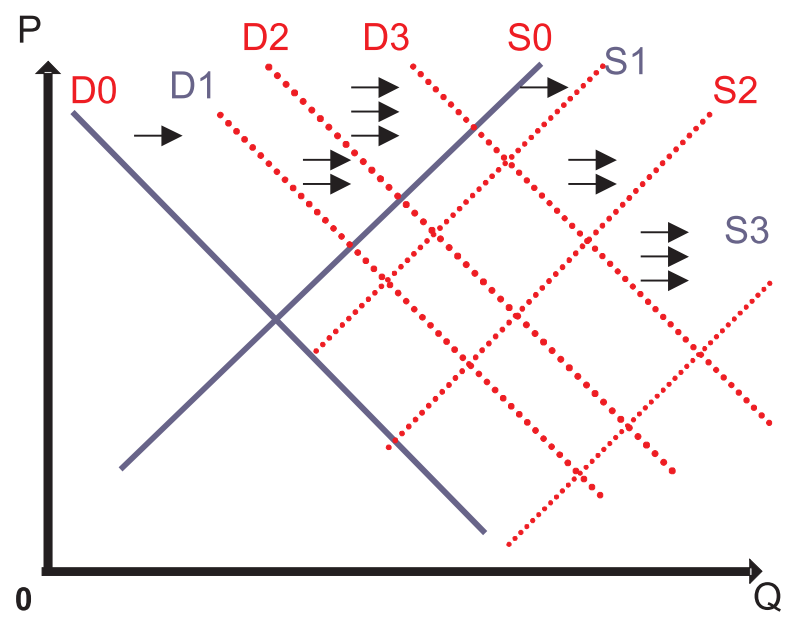

FIGURE 1 The diagram used by Class 2 to illustrate the effect of a simultaneous change in demand and supply on price. Note. $\mathrm{P}=$ price; $\mathrm{D}=$ demand; $\mathrm{S}=$ supply; $\mathrm{Q}=$ quantity. 


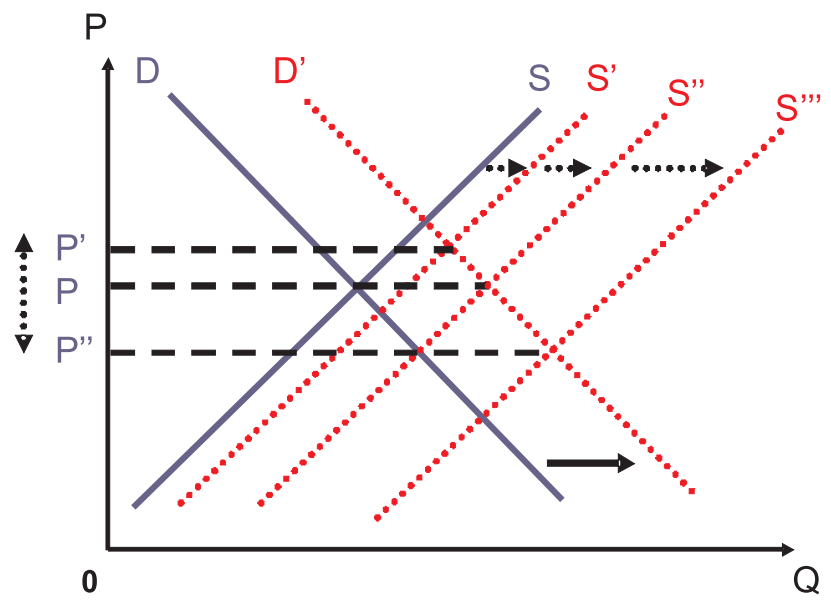

FIGURE 2 The diagram used by Class 1 to illustrate the effect of a simultaneous change in demand and supply on price. Note. $\mathrm{P}=$ price; $\mathrm{D}=$ demand; $\mathrm{S}=$ supply; $\mathrm{Q}=$ quantity.

moving, and in accordance with their continuous movements, the equilibrium price also moved continuously (see Figure 1).

What the students were supposed to experience, grasp, or imagine is that changes in price can be seen as a function of changes in the relative magnitude of changes in supply and demand as is shown by the continuous movements of the supply and demand curves from left to the right or the other way around. These continuous shifts can, of course, be imagined when looking at the same curve in two different positions, but they can actually be seen when the lines are moving. Hence, in one case, students have to see and imagine, and in the other case, they only have to see. Hence, ceteris paribus, the second case should yield at least as good a result as the first. We now look at the three different classes in the comparison group.

\section{Lived and Enacted Objects of Learning in the Comparison Group}

A highly surprising finding was the considerable difference in the results between Class 3 and the other two classes (see Table 6).

In the two other classes, only a few students reached the target (Conception E), whereas in this class, more than half of the students did so. How can we understand this difference? We look at the enacted object of learning in the three cases.

Class 3. Teacher 3 followed the lesson plan quite closely except that he did not complete a worksheet that dealt with a decrease in demand in the context of bus 
TABLE 6

Intragroup Comparison Between Classes in the Comparison Group:

Posttest—-the Lived Object of Learning (2)

\begin{tabular}{|c|c|c|c|c|c|c|}
\hline \multirow[b]{2}{*}{ Conception } & \multicolumn{2}{|c|}{ Class 3} & \multicolumn{2}{|c|}{ Class 4} & \multicolumn{2}{|c|}{ Class 5} \\
\hline & No. & $\%$ & No. & $\%$ & No. & $\%$ \\
\hline A & $0 / 32$ & 0.0 & $0 / 27$ & 0.0 & $0 / 33$ & 0.0 \\
\hline B & $1 / 32$ & 3.1 & $3 / 27$ & 11.1 & $9 / 33$ & 27.3 \\
\hline $\mathrm{C}$ & $0 / 32$ & 0.0 & $0 / 27$ & 0.0 & $1 / 33$ & 3.0 \\
\hline D & $10 / 32$ & 31.3 & $21 / 27$ & 77.8 & $21 / 33$ & 63.6 \\
\hline E & $21 / 32$ & 65.6 & $3 / 27$ & 11.1 & $2 / 33$ & 6.1 \\
\hline
\end{tabular}

services, and he did not finish the case of a decrease in demand and supply. Nonetheless, he thoughtfully combined the three separate diagrams that showed the three possible cases into one diagram, which helped the students to experience the variation in a more visible manner.

The pattern of variation and invariance inherent in the enacted object of learning can be seen in Table 7.

Class 4. Teacher 4 executed the lesson plan in a serious manner. However, she deviated from the lesson plan by omitting the discussion of the case of a simultaneous decrease in demand and supply. Nevertheless, she spent time on some add-ons such as talking about the distinction between a change in demand/supply and a change in the quantity demanded/supplied and how to derive a market supply. Last, in addition to the examples of slimming services and bus services, she used examples such as watermelons and sports shoes to explain the concept of an increase in supply.

The pattern of variation and invariance inherent in the enacted object of learning summarizes three lessons from the point of view of the variation framework (see Table 7).

Class 5. Teacher 5 carried out the lesson as planned without any additions. However, she did miss out some of the parts contained in the lesson plan in her actual implementation, namely, the part on decrease in demand as well as that on decrease in both demand and supply in the case of bus service. With regard to her explanation of the effect of simultaneous change on demand and supply on price change, she did not execute it very well and could not highlight the critical aspect of the relative magnitude of change in demand and supply, as she was disturbed by the misbehavior of students during the lesson.

The pattern of variation and invariance inherent in this enacted object of learning can be seen in Table 7 . 
TABLE 7

Patterns of Variation and Invariance (Temporal Sequence) Inherent in the Lessons in Classes 3, 4, and 5

\begin{tabular}{|c|c|c|c|c|c|c|}
\hline Supply & $\begin{array}{c}\text { Change in } \\
\text { Magnitude } \\
\text { (Supply) }\end{array}$ & Demand & $\begin{array}{c}\text { Change in } \\
\text { Magnitude } \\
\text { (Demand) }\end{array}$ & Goods & $\begin{array}{c}\text { Change in } \\
\text { Magnitude } \\
\text { (Relative) }\end{array}$ & Price \\
\hline \multicolumn{7}{|l|}{ Class 3} \\
\hline I & & V & & A & & V \\
\hline V & & I & & A & & V \\
\hline \multirow[t]{3}{*}{$\mathrm{V}$} & & V & & A & & V \\
\hline & V & & V & A & V & $\mathrm{V}^{\mathrm{a}, \mathrm{b}}$ \\
\hline & V & & V & B & V & $\mathrm{V}^{\mathrm{b}, \mathrm{c}}$ \\
\hline \multicolumn{7}{|l|}{ Class 4} \\
\hline I & & $\mathrm{V}^{\mathrm{d}}$ & & A & & V \\
\hline I & & $\mathrm{V}^{\mathrm{e}}$ & & B & & V \\
\hline $\mathrm{V}^{\mathrm{d}}$ & & I & & A & & V \\
\hline $\mathrm{V}^{\mathrm{d}}$ & & I & & $D \& E$ & & V \\
\hline & $\mathrm{V}^{\mathrm{d}}$ & & $\mathrm{V}^{\mathrm{d}}$ & A & $\mathrm{V}^{\mathrm{d}}$ & V \\
\hline \multicolumn{7}{|l|}{ Class 5} \\
\hline I & & $V^{f}$ & & A & & V \\
\hline$V^{f}$ & & I & & A & & V \\
\hline \multirow[t]{2}{*}{$V^{f}$} & & $V^{f}$ & & A & & $\mathrm{V}$ \\
\hline & $V^{f}$ & & $\mathrm{~V}^{\mathrm{f}}$ & A & V & V \\
\hline
\end{tabular}

Note. $\mathrm{V}=$ variation; $\mathrm{I}=$ invariance.

ancrease in both demand and supply only. ${ }^{\text {b}}$ The three cases $(<,>,=)$ were shown in the same diagram. ${ }^{c}$ Decrease in both demand and supply only. ${ }^{\mathrm{d}}$ Increase only. ${ }^{\mathrm{e}}$ Decrease only. ${ }^{\mathrm{f}}$ Increase only.

\section{A Comparison of the Three Classes in the Comparison Group}

Judging from the intended object of learning, we predicted that it would be difficult for the students in the comparison group to appropriate the object of learning. Nevertheless, it did happen in a number of cases, although in far fewer than in the target group. We have pointed out that the teacher of Class 4 did vary the goods that were used as examples in the cases of increasing and decreasing demand and the case of changing (increasing) supply. Thus, it was not possible to separate demand and supply from the goods. It was, however, possible to go beyond the information given and project demand or supply into either of the goods by sheer imagination. Nevertheless, this way is much harder than when the necessary pattern for discernment is directly accessible. It is also more difficult to discern changes in the magnitude of increase or decrease because the magnitude of change in the demand or supply does not vary only according to the intended object of learning. Again, the student might be able to block out other simultaneous variation and thus discern the magnitude of change in de- 
mand or supply, but this is much harder than in the case when only the magnitude of change in either demand or supply varies.

This explains how students can learn even when, from a strictly logical point of view, it is not possible to learn. How, then, can we explain why this mainly happened in Class 3 ?

In this class, the teacher did something that was critically different from the intended object of learning. Like Teachers 1 and 2, he brought together the graph lines that represented the different combinations of levels of demand and supply and made the variation in the relative magnitude of changes in demand and supply visible for the students. The necessary condition for grasping this concept is that the learners experience variation in the dimension to which it corresponds. By bringing the different functions together, he made it much easier for the students to experience variation by allowing them to experience the different positions simultaneously.

\section{DISCUSSION}

\section{What Makes the Difference Between Lessons?}

For this study, we report some rather dramatic differences in the outcome of learning. These differences are linked to specific differences in how the object of learning is handled in different classes in terms of variation and invariance as highlighted in the sections on the intended object of learning as well as on the lived and enacted objects of learning. These differences were to a significant extent associated with the teachers' awareness of the role of variation and invariance for learning as demonstrated in their lesson plans and in their way of conducting the lessons. The differences in what happened in the classroom were not differences in how the learning was organized: that is, in whether whole-class teaching, group work or individual study, a lecture-style arrangement, project work, or problem-based learning was employed. The differences occurred in how the object of learning was handled, structured, and presented. These differences were few in number and seemingly rather subtle, but we identify them as being critical differences according to the framework that was used by the teachers and according to the results that we (the researchers) interpreted using that framework. This means that even when curricular materials are good and the conditions of implementation fidelity are met, many microfeatures can come into play and undermine the best of curricular intentions.

The evidence of a single study is rarely conclusive, and the evidence from a single design experiment can never be so. However, the results from other studies point in the same direction. In these studies, by using the same framework, a few critical features of other objects of learning were identified. The necessary pattern 
of variation and invariance (the enacted object of learning) was brought about, which yielded striking differences in outcome (the lived object of learning) when a comparison was made with other conditions for mastering the same object of learning that lacked the necessary pattern of variation and invariance (see, e.g., Pang \& Marton, 2003; Lo et al., 2004).

\section{What Is Necessary for Learning?}

In this article, we briefly presented and illustrated a framework of learning in which what is necessary and what is a contingent are separated, with the necessary conditions being specific for each specific object of learning. The practical corollary of this framework is that learning should be enhanced by bringing about the necessary conditions for mastering the specific object of learning for every specific learning task. According to this framework, a particular pattern of variation and invariance is necessary to master every specific object of learning. We are not saying that such patterns of variation and invariance cannot be brought about by teachers who are ignorant of the framework because it is impossible to teach without using variation and invariance, and many teachers often intuitively create the necessary conditions for mastering the specific object of learning that they are dealing with (see, e.g., Marton \& Morris, 2002). We are merely suggesting that this is more likely to happen if the teacher is aware of the necessary conditions for mastering the specific object of learning.

Conversely, what the necessary conditions are in each specific case and how they can be brought about cannot be theoretically derived. Unless they have been identified and described earlier, they must be found anew for every new object of learning.

What the variation framework does is point to what to look for, the critical features, and the pattern of variation and invariance. It also points to the best source of insight into what is critical and what is necessary: the learners themselves.

Now, claiming that certain conditions of learning are necessary does not imply that these are the only necessary conditions. A necessary condition is, for instance, that the students are paying attention, that they are trying to learn. We are not dealing with this; we presuppose it. There are other conditions that are contingent but still might make a difference for learning. We are only looking at the examples used in class, for instance, in terms of similarities and differences. Examples, however, can be more or less interesting and more or less easy to grasp. Such differences can very well make significant differences for learning, but we are not dealing with them either. We are obviously not trying to present a comprehensive framework for analyzing and designing learning events but a rather specific framework that points to some necessary conditions of learning and not to others. 


\section{There Are No Teaching Experiments}

Embodied theory. If the design is a teaching design and is based on a framework that is subject to testing, then the framework has to be embodied in the teachers. Teaching is interactive, and successful teaching requires a continuous monitoring of this interaction whereby the teacher obtains information from the students that is necessary for deciding on the next move during a lesson. Teaching requires the teacher and the students to be mutually in touch, and thus, a teacher's moves cannot be predicted, much less prescribed. Exploring how an educational framework works in practice presupposes that the practitioner sees their practice in terms of that framework.

A learning study is thus a design experiment for which the teachers are the designers. At the same time, a learning study is a lesson study that is theoretically based, systematically grounded, and systematically evaluated.

"Error variance" as a source of insights. In laboratory experiments on learning, the effects of differences in conditions on differences in outcome are observed. If the outcomes differ and the compared conditions are alike in all but one respect, then we can connect the variation in outcome to the varying aspect of the compared conditions.

In a laboratory experiment, the conditions to be compared are supposed to be present in parallel or more or less simultaneously, whereas in a design experiment, the conditions to be compared succeed each other. In a design experiment, the experimenter looks at one condition or set of conditions at a time, studies the outcome, changes the condition by learning from it, and then compares both the changed condition with the previous unchanged condition and the outcomes of the two. Possible differences in outcome can then be related to differences in the conditions that are brought about by the change. This cycle of changing conditions that compares the conditions before and after change and relates these differences to differences in outcome can be repeated many times in a design experiment: indeed, all too many times, according to Dede (2004).

However, there is another kind of difference between conditions that is different both from the variables that are introduced by an experimenter in laboratory experiments on learning and from the differences that are brought about by the changes that are made by the designer in design experiments. In many learning studies, a group of teachers develops or designs the intended object of learning, which each teacher then sets out to implement in parallel. This was actually the case in the comparison group in this study. With such an arrangement, we find that the enacted object of learning differs between the different classes, even though they all derive from the same intended object of learning. Differences between the intended and the enacted object of learning and between different enacted objects of learning can be considered as error variance. However, when this kind of spontaneously 
generated difference is interpreted using the framework on which the intended object of learning is based and is related to differences in outcomes or gains in different classes, then the error variance may become a source of decisive insight.

Controlling or describing variation. A teacher's sensitivity to the reactions of the students to their teaching is essential for good teaching. At the same time, this sensitivity means that no teaching experiment -in the strict sense of experimental control-can ever truly be carried out. Remember, for instance, Teacher 3 in the comparison group who put the three diagrams together to illustrate the differences in the relative magnitude of changes in supply and demand, probably as a response to the fact that his students did not seem to understand what he was saying. This unplanned move was interpreted to be highly significant for the learning outcome.

We could not control the difference between what happened in Teacher 3's class and what happened in the other classes in the comparison group, and neither could we control the differences in what happened in the classrooms of Teachers 1 and 2 in the target group when Teacher 2 illustrated the three different combinations of supply and demand curves by means of two moving curves through a computer-implemented dynamic representation.

We may not have been able to control these differences, but we could describe them and relate them in a meaningful way to the differences in outcome; and by so doing, we made a minor discovery. It seems that to experience the effect of two simultaneously changing variables (supply and demand) on a third variable (price), it is an advantage for learners to be exposed to the different cases as represented in one diagram rather than separate diagrams. It is a further advantage for learners to be exposed to the changes represented as movements in a diagram (i.e., being represented dynamically) rather than simply being exposed to the changes as differences between different cases in the same diagram (i.e., being represented in static form).

Teaching thus cannot be predicted, much less prescribed; but it can be described. There cannot be any true teaching experiments, and design experiments in which control is substituted by description are necessary if one wishes to better understand the process of teaching.

\section{ACKNOWLEDGMENTS}

This research was made possible by grants from the Swedish Research Council (\#421-2002-35309) and the University of Hong Kong (\#200411159017).

\section{REFERENCES}

Barab, S., \& Squire, K. (2004). Design-based research: Putting a stake in the ground. The Journal of the Learning Sciences, 13, 1-14. 
Bransford, J. D., Brown, A. L. \& Cocking, R. R. (Eds.). (2000). How people learn: Brain, mind, experience, and school. Washington, DC: National Academy Press.

Bransford, J. D., \& Schwartz, D. L. (1999). Rethinking transfer: A simple proposal with interesting implications. Review of Research in Education, 24, 61-100.

Broudy, H. S. (1977). Types of knowledge and purposes of education. In R. C. Anderson, R. J. Spiro, \& W. E. Montague (Eds.), Schooling and the acquisition of knowledge (pp. 1-17). Hillsdale, NJ: Lawrence Erlbaum Associates, Inc.

Broudy, H. S. (1988). The uses of schooling. London: Routledge.

Brown, A. L. (1992). Design experiments: Theoretical and methodological challenges in creating complex interventions in classroom settings. The Journal of the Learning Sciences, 2, 141-178.

Cobb, P., Confrey, J., diSessa, A., Lehrer, R., \& Schauble, L. (2003). Design experiments in educational research. Educational Researcher, 32(1), 9-13.

Collins, A. (1992). Toward a design science of education. In E. Scandlon \& T. D. Shea (Eds.), New directions in educational technology (pp. 15-22). Berlin: Springer.

Collins, A., Joseph, D., \& Bielaczyc, K. (2004). Design research: theoretical and methodological issues. The Journal of the Learning Sciences, 13, 15-42.

Dede, C. (2004). If design-based research is the answer, what is the question? The Journal of the Learning Sciences, 13, 105-114.

diSessa, A. A., \& Cobb, P. (2004). Ontological innovation and the role of theory in design experiments. The Journal of the Learning Sciences, 13, 77-103.

Gibson, J. J. (1986). The ecological approach to visual perception. Hillsdale, NJ: Lawrence Erlbaum Associates, Inc.

Gibson, J. J., \& Gibson, E. J. (1955). Perceptual learning: Differentiation or enrichment? Psychological Review, 62, 32-41.

Hong Kong Examinations Authority. (1992). Annual report. Hong Kong: Author.

Hong Kong Examinations Authority. (1995). Annual report. Hong Kong: Author.

Kelly, A. E. (2003). Research as design. Theme issue: The role of design in educational research. Educational Researcher, 32(1), 17-20.

Kelly, A. E. (2004). Design research in education: Yes, but is it methodological? The Journal of the Learning Sciences, 13, 115-128.

Lo, M. L., Marton, F., Pang, M. F., \& Pong, W. Y. (2004). Towards a pedagogy of learning. In F. Marton \& A. B. M. Tsui (with P. Chik, P. Y. Ko, M. L. Lo, I. Mok, F. P. Ng, M. F. Pang, et al., Eds.), Classroom discourse and the space of learning (pp. 189-225). Mahwah, NJ: Lawrence Erlbaum Associates, Inc.

Marton, F., \& Booth, S. (1997). Learning and awareness. Mahwah, NJ: Lawrence Erlbaum Associates, Inc.

Marton, F., \& Morris, P. (2002). What matters? Discovering critical conditions of classroom learning. Göteborg, Sweden: Acta Universitatis Gothoburgensis.

Marton, F., \& Tsui, A. B. M. (with Chik, P. P. M., Ko, P. Y., Lo, M. L., Mok, I. A. C., Ng, F. P., Pang, M. F., et al.) (Eds.). (2004). Classroom discourse and the space of learning. Mahwah, NJ: Lawrence Erlbaum Associates, Inc.

Pang, M. F., \& Marton, F. (2003). Beyond "lesson study"-Comparing two ways of facilitating the grasp of economic concepts. Instructional Science, 31, 175-194.

Shavelson, R., Phillips, D. C., Towne, L., \& Feuer, M. J. (2003). On the science of education design studies. Educational Researcher, 32(1), 25-28.

Stigler, J. W., \& Hiebert, J. (1999). The teaching gap: Best ideas from the world's teachers for improving education in the classroom. New York: Free Press.

Yoshida, M. (1999). Lesson Study: A case study of a Japanese approach to improving instruction through school-based teacher development. Unpublished doctoral dissertation, University of Chicago, Chicago. 
Copyright of Journal of the Learning Sciences is the property of Lawrence Erlbaum Associates and its content may not be copied or emailed to multiple sites or posted to a listserv without the copyright holder's express written permission. However, users may print, download, or email articles for individual use. 